\title{
Analysis on the Application Principle of Waterscape Design in Modern Landscape
}

\author{
Jialing Shao \\ Heihe University \\ Heihe, China
}

\begin{abstract}
This paper has expounded the important role of waterscape in landscape. The author has illustrated waterscape characteristics in landscape design, and analyzed waterscape design elements and waterscape functions. It points out that it is the characteristic of modern landscape design to combine water and its unique style to coordinate with the whole landscape and to use as much water as possible.
\end{abstract}

Keywords—waterscape design; landscape design; traditional

\section{INTRODUCTION}

Water is closely related with our life. Water is the source of life and the most important condition for the survival of life. Water is life and civilization. It seems to be innate for people's love of water. Water can bring people comfort and make people calm or excited. Under different situations, people may feel differently when they see water. However, people live in the city with no water around, so it has become more and more important to increase waterscape in city landscape design.

\section{CHARACTERISTICS OF WATER IN LANDSCAPE DESIGN}

\section{A. The Morphological Characteristics of the Water.}

With no fixed shape, water is a colorless and tasteless liquid. In fact, the core of waterscape design is the shape of river, lake and fountain basin in landscape. The appearance of water also is affected by gravity. For example, moving water forms streams and waterfalls and keeps in a steady and balanced state under the influence of gravity.

\section{B. The Sound Characteristics of Water}

Water bickers, impacts object and forms different shape. The different flow of water could make different sound effects and form different waterscape characteristic in landscape design. The sound water of water could affect people's mood. For example, sea waves could make people calm; the sound of waterfall could make people exciting.

\section{Light Characteristics of Water}

The effects of water under light enable water to reflect surrounding environment vividly as a mirror. The surrounding landscape is like a painting on the water surface. A gentle breeze may ripple the surface of the water and the shape of shadow is broken. It is such a fun. Designers also use the refraction effect of water to design fantastic landscape.

\section{LANDSCAPE DESIGN OF WATER FUNCTIONS}

Water is an attractive element in landscape design. In Chinese tradition garden, there is almost no water. Water has a very import role in landscape planning. It can create a beautiful landscape to carefully design water and other landscape elements. Buildings surrounded by water may produce water taste and float on water like a castle in fairyland. The architecture sculpture in the water could create an interesting image. The bickers, the impacting sounds on rocks or under water complement natural rhythm and rhyme. We have a good foundation on waterscape art, so we can combine traditional waterscape design and modern landscape design to create a unique waterscape design that can make use of natural elements. We can take advantage of water in urban landscape to provide a harmonious and natural space for the residents.

The main function of water in the landscape design is its aesthetic function. The waterscape planning and design in an open space could give full play of water's aesthetic function. The landscape design with water could play its viewing function and coordinate the whole landscape. Designers should consider the changeable nature of water, define the visual the use in vision and then determine the form of water in garden.

The static function and dynamic function of water provide different beauty. The static water could give a quiet and comfortable feeling and relax the anchor of the heart, which is the most important aesthetic function of static water. The flow of water is a dynamic element that has direction and movement characteristics.

\section{A. Appreciating Characteristic.}

In public space waterscape environment is an important appreciating object. It is the key point in landscape design. It has aesthetic characteristics and certain connotation. Its different forms and plasticity of water could create rich visual effects. Its dynamic characteristic is also wonderful. For example, waterfall, fountain and water spray in the sun could create a rainbow and produce a dramatic effect. With the combination of architectural sculptures and followers and trees and other elements, it could reflect different color mode 
on the water. The modern waterscape and sculpture style enrich the waterscape with high appreciating value.

\section{B. Ornamental Characteristic.}

The waterscape is treated as an ornamental element which could embody the natural characteristic of water. Its natural characteristic could be use to set off and embellish landscape. In ornamental waterscape designers should define the principal and subordinate relationship. Its expression form is the characteristics of ornamental effect. It could play its good ornamental effect to design a lake in a small garden environment. The road surrounded by water could bring passerby natural breath and quiet atmosphere. We also could use water drops to create waterfalls to effectively decorate the special environment. The clear water is transparent. The clear water in swimming pool could create a wonderful effect under the function of light.

Its participating characteristic; the key is to mobilize audience to participate in waterscape. The following are three basic expression types of waterscape.

It could reflect the participating state by using the characteristic of water, such as drinking fountain and bath. They are traditional waterscape.

The leisure characteristic of water could provide a lot of fun to people. It may arouse and increase children's interest to play around pond.

The hydrophilic waterscape could provide direct contact or approach mode to people in close distance

\section{The Basic Methods to Create Waterscape}

\section{A. Still Water.}

The static pressure is everywhere in nature. In landscape design, we could use the static effect of river and lake to create an open landscape. The still water could reflect the sky and buildings. The depth of water and the color of water container could create different landscape effects. The still water and shadows on the water surface could form a static landscape. The static characteristic is widely used in Chinese garden design. For example, Kunming Lake in the Summer Palace has an open horizon and a wide expanse of mistcovered waters. The pool-bottom fountain decorated with colorful pebbles and the manmade lake are also good designs for the park. A special waterscape is showed before us by setting different display mode at the bottom of swimming pool. The Manduhai Park in Hohhot does not pursue large or charming scenes, but visitors may see the interweaving of water and land and feel calm and steady. The still water brings people with a feeling of quietness and comfort. It seems that we could anchor our soul here.

\section{B. TheFlow of Water.}

In a narrow zigzag shape, the width, height and changes of water are closely related to the effect. The flow of water could bring us with a good mood. It could create a lively and vivid atmosphere by using the design of small stream in the garden landscape. The bickers and impacting sound of water flow like the language of nature tell us a story. For example, the waterway in Qiaohua Shiji Community in Hohhot is impressive. The dynamic water flows across the plants. The rocks and other natural landscape could bring people back to nature. The different shapes of flowing water bring people different experiences. The waterscape and water flow in sight could bring a cool sense. The flowing water and other elements could create a variety of beautiful landscape.

\section{Falling Water}

The waterfall is a main form in natural water. The falling water could create various artificial environments. People could create different type of waterfall according to their interests. The waterscape has the characteristics of occupying a small space and producing changes. The waterfall could give life to movable space, which is very suitable for urban environment. For example, the waterfall wall in the square could not only enjoy people in vision but also create natural sound in city. At present, the cross-formational flow could express the natural state of water.

\section{Spraying Water}

The natural waterscape is rare. Most of water we see is created by man by using artificial pressure. The ancient European garden is also designed with waterscape which used mechanical power and the nozzle performance to create a variety of patterns. Combined with light and music, it creates a wonderful light and shadow effect. The music fountains in square and water screen film are good examples. Ruyi River Music Fountain in the east of Hohhot Town Hall is also a good waterscape design. The water sound could bring people out of noisy city and bring them peace. The jumpy spray could make people feel lively and relaxed.

\section{E. Inheritance of Traditional Waterscape in Modern Waterscape Design}

Chinese traditional architecture mainly refers to residential building. The space layout of residential courtyard is designed according to the axis of traditional architecture, which is the most important part in the courtyard space and the core part in Chinese traditional space. The traditional architectural courtyard also uses waterscape in landscape design. The layout of Chinese traditional waterscape in classic garden uses the symmetric pattern. The traditional design is particular about symmetry and nature. The landscape layout adopts geometric model and the axis design, which follows the principle of coordination between people and nature. Community landscape has the charm of Eastern Garden. In addition, it combines the western living space and creates an open space. The building is embraced by water. By using the double axis form, it creates a modern waterscape layout. It is a unique garden combining traditional culture and western style. It shows us a symmetrical form and balanced rhythm.

\section{CONCLUSION}

Water is the eternal theme of the garden and is one of the important elements in the landscape. Water has vitality. The natural water could bring dynamic noise, quietness and peace, 
and charming reflection. Waterscape is an important part in landscape design. Water provides us a living environment. Water is the most attractive element in landscape design. It could reflect surrounding landscape no matter it is still or dynamic. It could make music and create fun. It could be an art independently or combine with other arts, creating a unique style. The layout design of waterscape plays an important role in the whole space. In a public space, water is often used to organize space and attract sights. It could be the theme of appreciation in the environment. Therefore, we should pay more attention on waterscape design in landscape design in order to create a harmonious and coordinated environment.

\section{REFERENCES}

[1] Guo Jing, Model of Talent Cultivation for Higher Vocational Education. Higher Education Press, 2000

[2] Tan Haogiang, To Meet Third Climax in Computer Polarization. Tsinghua University Press, 2000

[3] Liu Hao, Prospects of Application of Computer Aided Design Technology in Landscape Design. Science Mosaic, 2005.8

[4] Yu Pengfei, Du Yishu, Analysis on Relationship between Computer Aided Design and Hand Painting in Art Design. The Science Education Article Collect, 2008.6

[5] Zhao Ming, Yang Mo, Esthetics Investigation of Computer Aided Design Teaching. Forum on Contemporary Education (Teaching Research), 2011.6

[6] Zhou Yi, Zhou Wei, Investigation of Teaching Method of Computer Aided Design Course. Economy Business, 2014 